\title{
BMJ Open Learning types and learning success in a structured diabetes education programme for patients with type 2 diabetes: study protocol of a prospective, longitudinal study
}

\author{
Thimo Morro, ${ }^{1}$ Astrid Fink, ${ }^{1}$ Solveig Carmienke, ${ }^{2}$ Thomas Frese,${ }^{2}$ \\ Sebastian Guenther ${ }^{1}$
}

To cite: Morro T, Fink A, Carmienke S, et al. Learning types and learning success in a structured diabetes education programme for patients with type 2 diabetes: study protocol of a prospective, longitudinal study. BMJ Open 2019;9:e030611. doi:10.1136/ bmjopen-2019-030611

- Prepublication history for this paper is available online. To view these files, please visit the journal online (http://dx.doi. org/10.1136/bmjopen-2019030611).

Received 22 March 2019 Revised 24 June 2019 Accepted 19 July 2019

D) Check for updates

(c) Author(s) (or their employer(s)) 2019. Re-use permitted under CC BY-NC. No commercial re-use. See rights and permissions. Published by BMJ.

${ }^{1}$ Institute of Medical Sociology, Martin-Luther-University HalleWittenberg, Halle, Germany ${ }^{2}$ Institute of General Practice and Family Medicine of the Medical Faculty, Martin-LutherUniversity Halle-Wittenberg, Halle, Germany

Correspondence to

Dr Astrid Fink;

astrid.fink@medizin.uni-halle.de

\section{ABSTRACT}

Introduction Diabetes mellitus (DM) has had a wideranging impact on healthcare politics. Secondary diseases and complications caused by diabetes are relevant cost and utilisation factors in the healthcare system. For decades, diabetes self-management education (DSME) has played a major role in the treatment of patients with type $2 \mathrm{DM}$ (T2DM). The aim of this training is to empower patients to actively influence their diabetes process by gaining knowledge about health-related behaviours, such as healthy nutrition and exercise, and cardiovascular risks. The aim of the project is to analyse the practice of structured diabetes education and the effects of different learning types of participants. This project focuses on the needs of socioeconomically deprived patients and aims to improve DSME for this group. This patient group has a higher prevalence of T2DM, more complications and worse therapy-relevant parameters.

Methods and analysis The study will be conducted as a prospective longitudinal study. Patients will be recruited in outpatient physician offices over a period of 12 months. Patients will be included if they are 18 years and older, have T2DM and are scheduled to participate in DSME for the first time. A pseudonymised, written survey with standardised questionnaires will be administered. The data will be analysed using inferential statistical methods, such as correlation analysis, regression models and variance analytical designs.

Ethics and dissemination The study will be carried out following the principles of the Declaration of Helsinki and good scientific standards. Ethical approval of the Ethics Review Committee of the Medical Faculty at Martin-LutherUniversity, Halle-Wittenberg, was obtained. All participants in the study will receive comprehensive information and will be included after written informed consent is obtained. The results will be published in international peer-reviewed journals and presented at several congresses. Trial registration number DRKS00016630

\section{INTRODUCTION}

State of research and scientific background

In high-income countries, such as Germany, type 2 diabetes mellitus (T2DM) has a

\section{Strengths and limitations of this study}

- The learning effects of people with type 2 diabetes will be considered respect to individual learning type.

- The study explicitly explores the learning requirements for socially deprived patients, a highly vulnerable group in healthcare, and contributes to the explanation of different learning outcomes.

- The results can help to improve training concepts to better help groups of patients who have benefited less due to their learning types.

- Due to the methodology of the written survey, we will not include participants with type 2 diabetes who do not read and write the German language.

- The project duration is limited to 3 years to focus only on short-term effects or initial behaviour changes.

wide-ranging impact on healthcare politics. In Germany, this is caused by the high prevalence of T2DM, which is between $7 \%$ and $8.6 \%$ of adults, based on population-related surveys and billing data from individual health insurance funds. ${ }^{12}$ The results vary depending on the age group studied and the database used. Furthermore, the illness is coupled with a higher morbidity and mortality, especially due to macrovascular and microvascular secondary diseases. ${ }^{3}{ }^{4}$ These complications are relevant cost and utilisation factors in the healthcare system. ${ }^{56}$ The treatment goal for T2DM patients according to medical guidelines includes the recommendation of a normal blood sugar level and metabolic control, as well as screenings for secondary diseases on a regular basis. ${ }^{6}$

For a long time, structured education programmes for patients with T2DM (diabetes self-management education (DSME)) have been an important component 
of the national medical care guideline and play a major role in the medical attendance and treatment of people with T2DM. ${ }^{5}$ National and international specialist societies recommend that these patients take part in DSME programmes and make the participation possible for all patients. ${ }^{5-9}$ The goal of this training is the empowerment of patients. This means that the affected individuals should learn how to influence the process of the illness by gaining knowledge about health-related behaviours, such as healthy nutrition and exercise, and cardiovascular risks. This knowledge should lead to a realisation of DM-specific treatment requirements of the patients. ${ }^{579-11}$ In addition, DM patients gain knowledge about secondary diseases, as well as skills to identify complications by themselves (eg, self-inspection of the feet to obtain an early diagnosis of diabetic foot syndrome). Structured and quality-controlled patient training courses are internationally approved procedures with a proven positive effect on relevant parameters, such as blood sugar level, glycated haemoglobin A1c (HbA1c), ${ }^{12-15}$ blood pressure and body weight. ${ }^{15-17}$ Additionally, they are also indicators of highquality medical care, such as the screening frequency for diabetic retinopathy. ${ }^{13161819}$ A recent systematic review by Odgers-Jewell et al provided evidence supporting the use of group-based education for the management of type 2 diabetes to improve several parameters. ${ }^{20}$ However, the results of the individual studies with regard to HbAlc level showed that there was a considerable degree of dispersion within the intervention group (group-based education). This could be interpreted carefully to mean that not all participants benefit equally from the DSME.

Evidence indicates that individuals with low socioeconomic status (a composite measure of an individual's economic and sociological standing in relation to others) and T2DM participate less frequently in diabetes education programmes ${ }^{21} 22$ and seem to have more barriers to diabetes self-management that seem to be less pronounced. ${ }^{23}{ }^{24}$ Furthermore, low individual socioeconomic status and residential area deprivation seem to be often associated with worse process indicators and intermediate outcomes. ${ }^{25}{ }^{26}$ In a previous qualitative study on the challenges posed by a diagnosis of T2DM, our research team found that even though almost all patients reported earlier participation in diabetes training, the results of the training were interpreted and implemented in very different ways. ${ }^{27}$ The learning processes for managing the disease were very different, which is also described in the literature. ${ }^{28}{ }^{29}$ In the study, we also found slight differences in dealing with the disease according to socioeconomic status, particularly the educational status of the individuals involved. Individuals with a lower educational level seemed to be more focused on their doctors as authorities and tried to strictly follow their recommendations. In a detailed manner, these individuals reported how they changed their lifestyle and how they implemented the treatment, even when this led to limitations and prohibitions in their lifestyle. ${ }^{27}$ This self-reported accurate realisation of the recommendations was not reported by all studies from Germany and other countries and is in contrast to the high frequency of T2DM-related complications and worse therapy relevant parameters in socioeconomically deprived patient groups. ${ }^{26}$ Persons with a higher educational level seemed to have different opinions and needs. They preferred to be recognised as competent patients, to be self-reliant in dealing with the disease and to maintain their current quality of life. ${ }^{27}$

The disease forces the patients with T2DM to learn to live with the disease. This distinguishes learning to live with diabetes from many other learning processes in adult learning. A comprehensive understanding of human learning is based on the work of Illeris. ${ }^{30} \mathrm{He}$ emphasises 'that all learning implies the integration of two very different processes, namely, an external interaction process between the learner and his or her social, cultural or material environment, and an internal psychological process of elaboration and acquisition'. These assumptions open up a triangular field that characterises three dimensions of learning: functionality (the learning content and the individual's capacity and understanding), sensitivity (the importance of the individual's incentive for learning: motivation, emotion and volition) and integration (the ways in which the individual can make sense of the learning; interaction with fellow learners or the environment). ${ }^{30}$ This understanding of learning takes into account the idea that learning takes place in a sociocultural context and has both a cognitive and an emotional level ${ }^{31}$ and seems appropriate to illuminate the extensive processes involved in learning diabetes self-management.

When considering why not all patients seem to benefit equally from training and why trained patients implement their findings very differently, one possible explanation seemed to be that the different learning outcomes may not be due to teaching methods alone, but to a specific interaction between teaching methods and learners' personality traits. ${ }^{32}$ We have, therefore, decided to take a closer look at the learning styles, taking into account different socioeconomic contexts of the patients affected by T2DM.

\section{Aims and research questions}

The aim of this study is to explore the practice of DSME for T2DM in central Germany and to analyse the impact of education on different types of patients according to learning type and socioeconomic status. Our current investigation aims to answer the following questions:

1. Do social inequalities manifest themselves in the participation of patients with T2DM in DSME?

2. Do social inequalities manifest themselves in type $2 \mathrm{di}$ abetes patients with different learning types?

3. For what type of learner are the DSME programmes most helpful?

4. How successful is DSME for T2DM patients with different learning types and socioeconomic statuses with respect to short-term effects? 


\section{METHODS AND ANALYSIS}

To answer the research questions, we planned a study in three German federal states (Saxony, Saxony-Anhalt and Thuringia), which have a higher prevalence of T2DM and a higher poverty rate than the average German population. The data collection will be conducted between May 2019 and November 2020.

\section{Study population}

The researchers seek to survey people with T2DM in an outpatient setting. The inclusion criteria will be:

1. Patients recently diagnosed with T2DM or receiving a therapy escalation due to T2DM.

2. Patients whose physicians encouraged them to participate in DSME for the first time.

3. Patients aged 18 years or older.

4. Patients with sufficient German language skills to answer the questionnaire.

Exclusion criteria:

1. Patients with another type of DM.

2. Patients who have already participated in DSME.

3. Patients for whom DSME is not indicated from the point of view of the attending physicians.

4. Patients with insufficient German language skills.

\section{Design}

The study is designed as a longitudinal study. All patients will receive a recommendation from their doctor to attend a DSME programme. There are some validated DSME programmes in Germany that have been certified by the Diabetes Society and can be used within the framework of the Disease Management Programmes for T2DM. ${ }^{12}{ }^{33-35}$ The selection of the DSME programme offered is the responsibility of the respective doctor's office. We will record the selection along with the data collected about the doctor's office. The actual decision of whether or not to attend the DSME programme will be made by the patient. Those participating in the training will be asked to complete a questionnaire before participation in the DSME (t1), at the end of the DSME (t2) and 6 months after the DSME (t3). The non-participants of the DSME will be surveyed twice, once right after inclusion in the study (t1) and again 6-9 months later (t3). By questioning this group twice, we want to illustrate what patients learn about their disease even without participating in a DSME programme. The schedule of the surveys is shown in figure 1.

\section{Outcomes}

This project focusses on the outcomes of (1) learning type and (2) learning success, both in association with socioeconomic status. Type of learning will be operationalised according to the types of learners in adult education of Schrader. ${ }^{36}$ This instrument was chosen because, to the best of our knowledge, it is the best-tested instrument in adult education for German-speaking countries. Translations of instruments from English were not available, and scientific quality is more important than

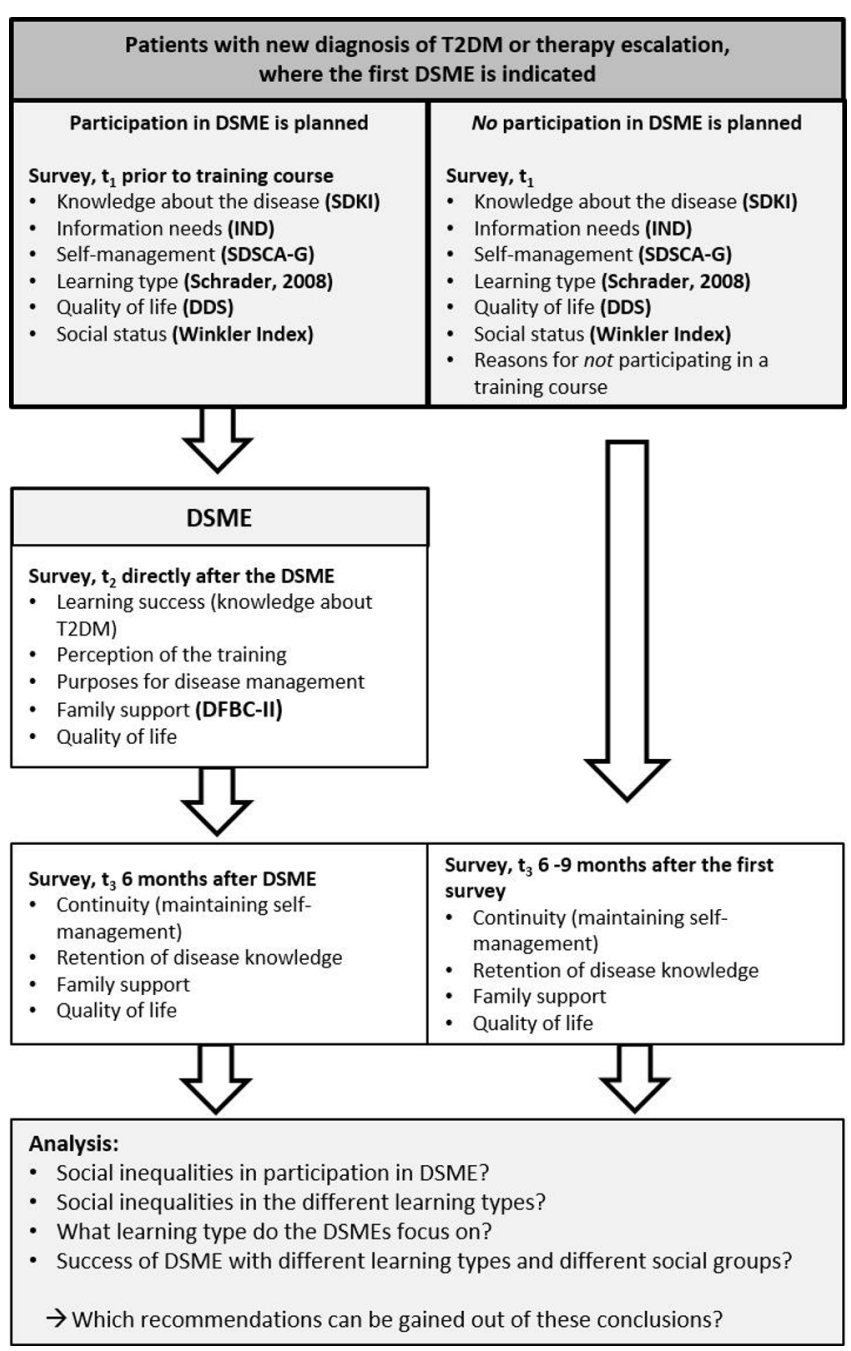

Figure 1 Schedule of surveys. DDS, Diabetes Distress Scale; DFBC-II, Diabetes Family Behaviour ChecklistII; DSME, diabetes self-management education; IND, information needs in diabetes; SDKI, short diabetes knowledge instrument; SDSCA-G, Summary of Diabetes SelfCare Activities Measure (German); T2DM, type 2 diabetes mellitus; Winkler Index, an index of socioeconomic status that combines educational attainment, occupational status and income into one indicator.

international representation. ${ }^{37}$ Schrader's descriptions correspond to the concept of learning styles in the international context. However, he decided to present his results with the help of ideal-typical people, and thus discussed the existence of different types of learners. The five types of learners include the theoretician, the application-oriented learner, the model student, the indifferent learner and the insecure learner. ${ }^{36}$ Four of the five types of learners can be classified based on the research of Marton, Entwistle and others. The theoretician and the application-oriented learner have an active, 'deep' style of learning that is aimed at understanding, which distinguishes them from the model student and the insecure learner. These individuals are better characterised by a receptive style of learning that focuses on knowledge accumulation and reproduction. ${ }^{36-40}$ Schrader stresses 
that learning behaviour can only be understood against the background of motivation, which can again be traced back to the three dimensions of learning and competence developed by Illeris. ${ }^{30}$

The second outcome, learning success, will be measured based on disease-specific knowledge and self-management skills. To assess socioeconomic status, we will use a composite measure of level of education, occupational status and net household income (Winkler Index). ${ }^{41}$ Further secondary outcomes will be quality of life (measured by the Diabetes Distress Scale ${ }^{42}$ and glycated HbA1c (reported by the patient from the 'diabetes passport'). Both should be improved by learning success. The learning success will be analysed in relation to various indicators, such as family support, expectations of the training course or reasons for not participating in a training course, purposes for disease management and perception of the training.

\section{Participant timeline}

\section{Sample size}

The sample size calculation is difficult because the expected effect sizes cannot be easily estimated, as this is the first time this topic will be examined. According to general rules for regression analyses, approximately 30 observation units are required for a linear regression model with one independent and one dependent variable. The number of observation units for each additional independent variable increases by 10 cases. ${ }^{43}$ To create a model with 32 independent variables (or characteristic values for categorical variables) for those affected by training, approximately 340 evaluable cases are required for the following steps. To reach this number, we aim to recruit 700 DSME participants. Estimating a response of $70 \%$ and a loss to follow-up of $30 \%$ after the DSME programme, we expect approximately 340 analysable cases. In the group of participants who declined to participate in a DSME programme, we expect a higher non-response rate. Therefore, we aim to recruit 700 potential participants for this group to reach the target value of 340 analysable cases.

\section{Recruitment procedure and data collection}

The patients will be recruited via a sample of outpatient practices in central Germany (Saxony, Saxony-Anhalt and Thuringia). The doctor's offices will be primary care practices subspecialised in diabetology, outpatient specialist practices of internal medicine and outpatient specialist practices for internal medicine, specialised in diabetology and/or endocrinology. The practice owners will be contacted in writing, briefly informed about the study and asked to support the project by recruiting study participants. A fax form will be enclosed for their reply, with which the practice owners can indicate their willingness to support or reject the project. Doctors who do not respond by fax will be called and asked for their decision. The staff of the Institute of General Practice and Family Medicine (IAM) will especially support the practice and patient recruitment process. The practice nurse or the nurse specialised in diabetes advice working as instructors in DSME programmes will be in charge of informing and recruiting the patients. Therefore, the project team of the Institute of Medical Sociology (IMS) and IAM will inform the practice nurse or the diabetes assistant, respectively, about the study. The recruiters will also receive a brief overview sheet to help them to identify appropriate patients to inform them about the study.

Patients who meet the inclusion criteria will be informed about the study by the practice nurse, and information material will be given to the patients. If contacted patients are willing to participate, they will immediately receive the study material, including the declaration of consent, a clarification letter, the t1 questionnaire, a separate declaration of participation in the follow-up survey and a return envelope. Patients can only participate if they provide written informed consent. After completing the questionnaire, participants should send it back to the IMS of Martin-Luther-University Halle-Wittenberg by mail in a prepared envelope. To separate the personal data from the survey questionnaire, two envelopes should be sent back to the study head office. One envelope will contain the declaration of consent and the completed questionnaire, and the other will contain the reply card with the participant's personal address for the follow-up survey. Envelopes are opened in a secure environment in the IMS to separate the declarations with the patients' addresses from the study questionnaires. Then, both the declarations and the questionnaires will be registered separately to prevent easy linkage of the questionnaires to the personal data, such as name and address, of the participants. However, it is necessary to connect both types of data because this study has multiple survey waves. Thus, a separate database will be developed. Using this database, questionnaires and participants can be reconnected. Only trustworthy members of the participating institutions will have access to the database but not to the questionnaires. Patients who declare their willingness to participate in the follow-up in $\mathrm{t} 1$ will receive the $\mathrm{t} 2$ or $\mathrm{t} 3$ questionnaire by mail and will be asked to complete it and send it back to the IMS. In the t2 and t 3 questionnaires, the participants will receive study information as a refresher and another declaration of consent. This declaration provides information about the voluntariness of participation in the study and the right to withdraw. Further information on data protection procedures can be found in the 'Data management and data safety monitoring' section.

The data collection will take approximately 18 months. This period is necessary to recruit enough participants (approximately 1 year of recruitment) and ensure sufficient time to send a t3 questionnaire to the last recruited patients 6 months after participating in the training. The data acquisition should be completed in August 2020. 
Table 1 Target factors and survey instruments used in the surveys

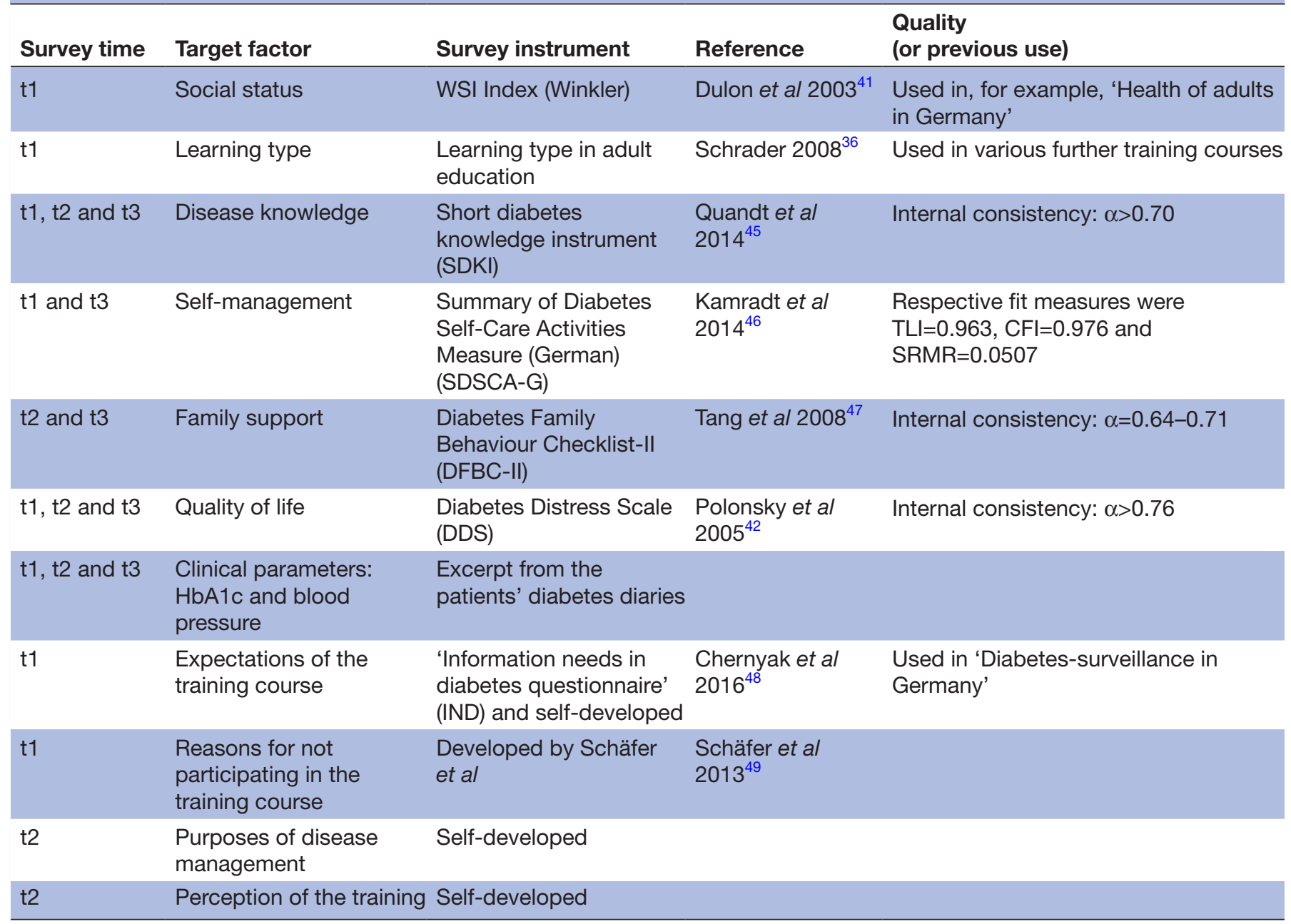

CFI, comparative fit index; HbA1c, haemoglobin A1c; SRMR, standardized root mean square residual; TLI, Tucker Lewis index.

\section{Sources of data}

We will administer pseudonymised, written surveys with standardised questionnaires. The content of the surveys with different measurement points is presented in table 1 . If possible, validated survey instruments will be used. The study questionnaire was pre-tested before the start of the survey. For this purpose, people who correspond to the target group were asked to fill out the questionnaire and to answer a few written and verbal questions. The primary focus was on the clarity of the questions, explanations of the possible answers and the appropriateness of the content. The length and complexity of the questionnaire were also assessed. The feedback has been used to revised the content, which will improve the study quality.

In addition, training concepts that are permitted for the structured patient training of the Disease Management Programmes were evaluated using the CIPP model (CIPP is an acronym for Context, Input, Process and Product) developed by Stufflebeam and Zhang ${ }^{44}$ and by performing an input examination.

\section{Data management and data safety monitoring}

The data will be entered by science staff and student assistants at the IMS into specially created databases. A distinction will be made between address data and survey data. The study will be carried out using pseudonyms. All participants will be assigned a personal identification number (PIN) for pseudonymisation, and this number will be assigned to all survey data (questionnaires t1-t3). Neither names nor addresses will be stored in the survey database, these data will be managed in an independent address database in which the PINs are also stored. Both databases will be stored separately and will not be linked. The address database will be password-protected and stored locally on a personal computer (PC), without any network connexion. The survey database will be stored on a network drive belonging to a server of the University Hospital Halle (Saale). Access to this network drive will only be permitted to employees involved in the study, which is guaranteed by technical means. To determine the addresses for the t 2 and $t 3$ follow-up surveys, the PINs will be extracted from the survey database using a filter question and imported into the address database via 
a separate file. This ensures that there is no direct link between the two databases at any time. Thus, no conclusions can be drawn about specific individuals. If a participant withdraws his/her consent and asks for the survey data to be deleted, the reverse path will be taken. The PIN will be determined from the address database and all related survey data will be deleted. However, this will only be possible until the end of the survey phase. Then, all PINs in the address database will be deleted. If the consent is withdrawn, only the names and addresses of the respective individuals can be deleted from that point on. The question of whether the respondent planned to participate in a DSME at time $\mathrm{t} 1$ will serve as a filter for sending the t2 questionnaires. For all individuals who answered this question with 'yes', the PINs will be extracted from the survey database and stored in a separate file. This file, which contains only the PINs and the t2 note, will then be imported into the address database, with the PINs acting as link keys. The addresses to which a t2 questionnaire is sent will be determined based on the individuals who agreed to participate in the $\mathrm{t} 2$ survey. If it is noted in the address database that the persons did not want to participate in another survey, no questionnaire will be sent to them. The response to the question in the questionnaire database regarding the expected participation in a structured patient training course will also serve to differentiate between the $\mathrm{t} 3$ questionnaires. Individuals who originally (t1) did not intend to participate in a patient training course will receive a slightly modified t3 questionnaire that addresses the reasons why the individual chose not to participate. The PINs will also be filtered, extracted and stored in a separate file that is fed into the address database used to send out the t3 questionnaire. If the respondents agreed to a further survey at $\mathrm{t} 1$ or later (t2), the respective questionnaire will be sent to them. With the second and third submission of the questionnaire, the participants will be reminded of the upcoming survey. If necessary, supplementary postcards will be sent in follow-up campaigns to increase the response rate.

All members of the study staff are contractually bound to secrecy. In addition, they have been informed about the special requirements of data protection and sensitised to the related concerns. All PCs have exclusively password-protected user accounts and are located in premises with limited locking authorisations (digital locking system). This ensures that only authorised persons have access to the survey data. The address database is only accessible to one person. The original questionnaires are stored separately from the returned declarations of consent in different cabinets in the IMS archive. The archive is secured by a digital locking system. Each cabinet has its own key, the issuance of which is controlled by the head of the office.

\section{Data analysis}

Depending on the data available (eg, questionnaires issued vs completed questionnaires), simple difference tests will be used for the dropout analysis. In addition to the descriptive representation of the data in the first step, the data will be cross-sectionally and longitudinally analysed using inferential statistical methods, such as correlation analysis, regression models, factor analysis and variance analytical designs. The selection of the statistical method depends on the scale features and distribution of the variables (eg, variance homogeneity and group size). The significance level of the statistical tests will be set at $\alpha=0.05$. Considering that the study is an exploratory analysis without hypothesis testing, there will not be an alpha-adjustment for multiple tests. The results of the data analysis will be discussed by the science staff of both IAM and IMS, and the IAM staff, in particular, will contribute to the primary care perspective.

\section{Benefit-risk consideration}

The aim of this research project is not to provide direct benefits to the participating individuals, instead, the purpose is to use the study results to improve DSME, especially for socially disadvantaged people with T2DM, to provide long-term benefits. Accordingly, the use of targeted messaging to develop a better style of training is the ultimate goal. Patients who have not been profiting from the already existing programme can be more easily reached, thereby reducing inequalities in the usage and success of structured diabetes training programmes. Even if there is no individual benefit from participating in the project for the participants, the risks or potential complications of a questionnaire survey are low. The possibility that patients in the study may ask the project team for advice regarding treatment and general problems is considered. For that reason, offers of assistance or referral will be prepared.

\section{Patient and public involvement}

Three years ago, one of the principal investigators $(\mathrm{AF})$ conducted a qualitative study to investigate the challenges associated with a diagnosis of T2DM for those affected and the subjective perspectives of the patients under the conditions of the German healthcare system. ${ }^{27}$ In the course of the study, the study team discovered that even people with diabetes who had participated in training measures interpreted what they had learnt and implemented it in very different ways. The question of whether the structured patient education training programmes address different learning types equally stems directly from the findings of the patient-centred project.

The present study design is an established design for the assessment of the increase in knowledge. The principles of good scientific practice are the guiding principles. The target group of the study was not included in the development of the design or the questionnaire, but established survey instruments will be used as much as possible. The questionnaire has been tested in a pre-test group along with the target group, and their feedback will be taken into account in a revision to the extent that the validated scales allow. The results of the study will be published on the project homepage in an easily understandable, 
barrier-free manner. In addition, the cooperating practices will receive our publications for their use and the results can be disseminated to patients.

\section{ETHICS AND DISSEMINATION}

The study will be carried out according to the principles of the revised Declaration of Helsinki (Fortaleza 2013) and good scientific standards. All participants of the study will be extensively informed about the aim and procedures of the project, as well as the use of the collected data. Based on the General Data Protection Regulation, written informed consent will be obtained by the IMS. Participation in data acquisition is voluntary and can be withdrawn at any time. In this situation, data that have already been collected will be deleted by request. Non-participants will not face any consequences. The results will be published in multiple international, high-end, peer-reviewed journals, and it is our goal to present them at certain corresponding conventions and medical congresses.

Acknowledgements We would like to thank the participants of our first study, as the challenges posed by a diagnosis of type 2 diabetes mellitus (Fink et al., 2019) have allowed us to recognise the need to take learning types and learning success in a structured diabetes education programme into account. We acknowledge the financial support within the funding programme Open Access Publishing by the German Research Foundation (DFG).

Contributors TM wrote the initial draft of the manuscript. TF and AF led the grant application and acted as principal investigators. AF wrote the study protocol for the Ethics Review Committee. SG and SC are responsible as project scientists for the implementation, evaluation and publication of the study and gave critical comments to this manuscript. SG was responsible for the data protection concept, the choice of instruments (in collaboration with $\mathrm{AF}$ and $\mathrm{SC}$ ) and the design of the questionnaires. All the authors have read and approved the final version of the manuscript.

Funding This work was supported by the Wilhelm-Roux Program of the medical faculty of Martin-Luther-University, Halle-Wittenberg, for a period of 36 months.

Competing interests None declared.

Patient consent for publication Patients provide written informed consent to participate in the study. They are informed that findings from the study are only published with anonymous data that do not allow conclusions to be drawn about individual persons.

Ethics approval The Ethics Review Committee at the Martin-Luther-University, Halle-Wittenberg, granted approval (№.: 2018-142).

Provenance and peer review Not commissioned; externally peer reviewed.

Open access This is an open access article distributed in accordance with the Creative Commons Attribution Non Commercial (CC BY-NC 4.0) license, which permits others to distribute, remix, adapt, build upon this work non-commercially, and license their derivative works on different terms, provided the original work is properly cited, appropriate credit is given, any changes made indicated, and the use is non-commercial. See: http://creativecommons.org/licenses/by-nc/4.0/.

\section{REFERENCES}

1. Jacobs E, Tamayo T, Rathmann W. Epidemiologie des Diabetes in Deutschland. In: Deutsche diabetes Gesellschaft und diabetesDE Deutsche Diabetes-Hilfe, ED. Deutscher Gesundheitsbericht diabetes 2017: die Bestandsaufnahme. Mainz: Kirchheim + Co GmbH, 2017: 10-21.

2. Tamayo T, Brinks R, Hoyer A, et al. The prevalence and incidence of diabetes in Germany. Dtsch Arztebl Int 2016;113:177-82.

3. Icks A, Dickhaus T, Hörmann A, et al. Differences in trends in estimated incidence of myocardial infarction in non-diabetic and diabetic people: Monitoring Trends and Determinants on Cardiovascular Diseases (MONICA)/Cooperative Health Research in the Region of Augsburg (KORA) registry. Diabetologia 2009;52:1836-41.

4. Du Y, Heidemann C, Gößwald A, et al. Prevalence and comorbidity of diabetes mellitus among non-institutionalized older adults in Germany - results of the national telephone health interview survey 'German Health Update (GEDA)' 2009. BMC Public Health 2013;13:166.

5. Bundesärztekammer (BÄK), Kassenärztliche Bundesvereinigung (KBV), Arbeitsgemeinschaft der Wissenschaftlichen Medizinischen Fachgesellschaften (AWMF). Nationale VersorgungsLeitlinie diabetes - Strukturierte Schulungsprogramme. 1st edn. Langfassung, 2012.

6. Bundesärztekammer (BÄK), Kassenärztliche Bundesvereinigung (KBV), Arbeitsgemeinschaft der Wissenschaftlichen Medizinischen Fachgesellschaften (AWMF). Nationale VersorgungsLeitlinie therapie des Typ-2-Diabetes. 4. Langfassung. 1. Auflage, Version, 2014.

7. Powers MA, Bardsley J, Cypress M, et al. Diabetes self-management education and support in type 2 diabetes. Diabetes Educ 2017;43:40-53.

8. International Diabetes Federation. IDF clinical practice recommendations for managing type 2 diabetes in primary care, 2017. Available: www.idf.org/managing-type2-diabetes [Accessed 13 Dec 2018].

9. National Institute for Health and Care Excellence (NICE). Type 2 diabetes in adults: managemen type 2 diabetes in adults: management, 2017. Available: https://www.nice.org.uk/guidance/ ng28 [Accessed 13 Dec 2018].

10. Deakin TA, McShane CE, Cade JE, et al. Group based training for self-management strategies in people with type 2 diabetes mellitus. Cochrane Database Syst Rev 2005;2.

11. American Diabetes Association. Standards of medical care in diabetes-2015 abridged for primary care providers. Clin Diabetes 2015;33:97-111.

12. Hermanns N, Kulzer B, Maier B, et al. The effect of an education programme (MEDIAS 2 ICT) involving intensive insulin treatment for people with type 2 diabetes. Patient Educ Couns 2012;86:226-32.

13. Ellis SE, Speroff T, Dittus RS, et al. Diabetes patient education: a meta-analysis and meta-regression. Patient Educ Couns 2004:52:97-105

14. Minet L, Møller S, Vach W, et al. Mediating the effect of self-care management intervention in type 2 diabetes: a meta-analysis of 47 randomised controlled trials. Patient Educ Couns 2010;80:29-41.

15. Weitgasser R, Clodi M, Cvach S, et al. [Diabetes education and counselling in adult patients with diabetes (Update 2019)]. Wien Klin Wochenschr 2019;131(Suppl 1):110-4.

16. Pillay J, Armstrong MJ, Butalia S, et al. Behavioral programs for type 2 diabetes mellitus: a systematic review and network meta-analysis. Ann Intern Med 2015;163:848-60.

17. Powers MA, Bardsley J, Cypress M, et al. Diabetes self-management education and support in type 2 diabetes: a joint position statement of the American diabetes association, the American association of diabetes educators, and the Academy of nutrition and dietetics. $J$ Acad Nutr Diet 2015;115:1323-34.

18. Knight $\mathrm{K}$, Badamgarav $\mathrm{E}$, Henning JM, et al. A systematic review of diabetes disease management programs. Am J Manag Care 2005;11:242-50.

19. Mulcahy K, Maryniuk M, Peeples M, et al. Diabetes selfmanagement education core outcomes measures. Diabetes Educ 2003;29:768-803.

20. Odgers-Jewell K, Ball LE, Kelly JT, et al. Effectiveness of groupbased self-management education for individuals with type 2 diabetes: a systematic review with meta-analyses and metaregression. Diabet Med 2017;34:1027-39.

21. Adjei Boakye E, Varble A, Rojek R, et al. Sociodemographic factors associated with engagement in diabetes self-management education among people with diabetes in the United States. Public Health Rep 2018;133:685-91.

22. Horigan G, Davies M, Findlay-White F, et al. Reasons why patients referred to diabetes education programmes choose not to attend: a systematic review. Diabet Med 2017:34:14-26.

23. Vissenberg C, Stronks K, Nijpels G, et al. Impact of a social network-based intervention promoting diabetes self-management in socioeconomically deprived patients: a qualitative evaluation of the intervention strategies. BMJ Open 2016;6:e010254.

24. Onwudiwe NC, Mullins CD, Winston RA, et al. Barriers to selfmanagement of diabetes: a qualitative study among low-income minority diabetics. Ethn Dis 2011;21:27-32.

25. Ricci-Cabello I, Ruiz-Pérez I, Olry de Labry-Lima A, et al. Do social inequalities exist in terms of the prevention, diagnosis, treatment, control and monitoring of diabetes? A systematic review. Health Soc Care Community 2010;18:572-87. 
26. Grintsova O, Maier W, Mielck A. Inequalities in health care among patients with type 2 diabetes by individual socio-economic status (Ses) and regional deprivation: a systematic literature review. Int J Equity Health 2014:13:43.

27. Fink A, Fach E-M, Schröder SL. 'Learning to shape life' - a qualitative study on the challenges posed by a diagnosis of diabetes mellitus type 2. Int J Equity Health 2019;18:19.

28. Newton P, Asimakopoulou K, Scambler S. A qualitative exploration of motivation to Self-Manage and styles of self-management amongst people living with type 2 diabetes. J Diabetes Res 2015;2015:1-9.

29. Kneck Åsa, Fagerberg I, Eriksson LE, et al. Living with diabetesDevelopment of learning patterns over a 3-year period. Int J Qual Stud Health Well-being 2014;9:24375.

30. Illeris K. A comprehensive understandimg of human learning. In: Illeris K, ed. Contemporary theories of learning: learning theorist in their own words. London. New York, NY: Routledge Taylor \& Francis Group, 2018: 15-32.

31. Pätzold $\mathrm{H}$. Learning and teaching in adult education: contemporary theories. Opladen u. a.: Budrich, 2011.

32. Cronbach LJ, Snow RE. Aptitudes and instructional methods: a Handbook for research on interactions. New York: Irvington, 1977.

33. Gruesser M, Bott U, Ellermann P, et al. Evaluation of a structured treatment and teaching program for non-insulin-treated type II diabetic outpatients in Germany after the nationwide introduction of reimbursement policy for physicians. Diabetes Care 1993;16:1268-75.

34. Gruesser M, Hartmann P, Schlottmann N, et al. Structured treatment and teaching programme for type 2 diabetic patients on conventional insulin treatment: evaluation of reimbursement policy. Patient Educ Couns 1996;29:123-30

35. Hermanns N, Ehrmann D, Schall S, et al. The effect of an education programme (MEDIAS 2 BSC) of non-intensive insulin treatment regimens for people with Type 2 diabetes: a randomized, multi-centre trial. Diabet Med 2017;34:1084-91.

36. Schrader J. Lerntypen bei Erwachsenen. 2nd edn. Bad Heilbrunn: Verlag Julius Klinkhardt, 2008.

37. Cassidy * S. Learning styles: an overview of theories, models, and measures. Educ Psychol 2004;24:419-44.
38. Schmeck RR. An Introduction to Strategies and Styles of Learning. In: Schmeck RR, ed. Learning strategies and learning styles. Boston, MA: Springer US, 1988: 3-19.

39. Marton F. Describing and improving Learning. In: Schmeck RR, ed. Learning strategies and learning styles. Boston, MA: Springer US, 1988: 53-82.

40. Noel E. Motivational Factors in Students' Approaches to Learning. In: Schmeck RR, ed. Learning strategies and learning styles. Boston, MA: Springer US, 1988: 21-51.

41. Dulon M, Bardehle D, Blettner M. [Assessing social inequality in microcensus data and German national health examination survey] Gesundheitswesen 2003;65:629-35.

42. Polonsky WH, Fisher L, Earles J, et al. Assessing psychosocial distress in diabetes: development of the diabetes distress scale. Diabetes Care 2005;28:626-31.

43. Verma JP. Data analysis in management with SPSS software. New Delhi: Springer, 2013.

44. Stufflebeam DL, Zhang G. The CIPP evaluation model: how to evaluate for improvement and accountability. New York, London: The Guilford Press, 2017.

45. Quandt SA, Ip EH, Kirk JK, et al. Assessment of a short diabetes knowledge instrument for older and minority adults. Diabetes Educ 2014;40:68-76.

46. Kamradt M, Bozorgmehr K, Krisam J, et al. Assessing selfmanagement in patients with diabetes mellitus type 2 in Germany: validation of a German version of the summary of diabetes selfcare activities measure (SDSCA-G). Health Qual Life Outcomes 2014;12:185.

47. Tang TS, Brown MB, Funnell MM, et al. Social support, quality of life, and self-care behaviors among African Americans with type 2 diabetes. Diabetes Educ 2008;34:266-76.

48. Chernyak N, Stephan A, Bächle C, et al. Assessment of information needs in diabetes. Prim Care Diabetes 2016;10:287-92.

49. Schäfer I, Küver $C$, Wiese $B$, et al. Identifying groups of nonparticipants in type 2 diabetes mellitus education. Am J Manag Care 2013;19:499-506. 